\title{
Early Cardiac Resynchronization Therapy (CRT) improves the outcome in Heart Failure (HF) patients with Left Bundle Branch Block (LBBB)
}

\section{Un precoce trattamento di resincronizzazione cardiaca (CRT) migliora la prognosi in pazienti con scompenso cardiaco e blocco di branca sinistro}

\author{
Mario Stanislao1, Antonio Facciorusso1, Serena Michelini2, \\ Giovanni de Luca1, Mario Fanelli3, Guido Valle4
}

Monaldi Arch Chest Dis 2012; 78: 109-110.

1 Cardiology Unit, Scientific Institute "Casa Sollievo della Sofferenza", San Giovanni Rotondo, Italy.
2 University of Roma "La Sapienza" - Second School of Medicine, Roma, Italy.
3 University of Foggia, Cardiology Medical School.
${ }^{4}$ Nuclear Medicine Unit, Scientific Institute "Casa Sollievo della Sofferenza", San Giovanni Rotondo, Italy .

Corresponding author: Dott. Mario Stanislao, MD; Cardiology Unit; IRCCS “Casa Sollievo della Sofferenza”; 71013 San Giovanni Rotondo (FG), Italy; E-mail address: e-mail:mstani@alice.it; m.stanislao@operapadrepio.it; tel.+390882 410907; fax +390882410492

Dear Editor,

an accurate selection of the patients and a right instituting CRT timing are critical to get the most favourable outcome. For these reasons we greatly appreciated the paper by Penn and associates entitled "Improved outcome with preventive cardiac resynchronization therapy in the elderly: a MADIT-CRT substudy" recently appeared on the Journal of Cardiovascular Electrophysiology [1].

This paper in fact adds additional evidence to our previous works $[2,6]$ stating that CRT should be performed when left ventricular enlargement and remodeling are not severe. At this regard, using indexed data (i.e. ventricular volume data/body surface area expressed as $\mathrm{ml} / \mathrm{square}$ meter) we found out that CRT was effective only in patients with an indexed left ventricular end-diastolic volume (iLVEDV $<142 \mathrm{ml} / \mathrm{m}^{2}$ ) at pre-CRT gated Single Photon Emission Computed Tomography (gSPECT). In patients with indexed left ventricular dimensions below this threshold CRT usually produces a significant (i.e. $\geq 0.05$ ) LVEF increase. The increase of LVEF $\geq 0.05$ was used to as a threshold to classify responders and non responders. In our series, responders showed a mean baseline $\operatorname{LVEF}(0.24 \pm$ $0.08)$ significantly higher than non responders $(0.20$ $\pm 0.07)$. At pre-CRT study responders showed mean indexed end-systolic volumes (iESV) and indexed end-diastolic volumes (iEDV) significantly smaller than non responders. In fact in our series pre-CRT $\mathrm{iESV}$ resulted $97 \pm 37 \mathrm{ml} / \mathrm{m}^{2}$ in responders $v s 158 \pm$ $44 \mathrm{ml} / \mathrm{m}^{2}$ in non responders and pre-CRT iEDV was $126 \pm 38 \mathrm{ml} / \mathrm{m}^{2}$ in responders vs $196 \pm 43 \mathrm{ml} / \mathrm{m}^{2}$ in non responders. In responders CRT produced a significant reduction of both $\mathrm{iESV}$ and $\mathrm{iEDV}$ that pas- sed from $97+37 \mathrm{ml} / \mathrm{m}^{2}$ and $126+38 \mathrm{ml} / \mathrm{m}^{2}$ to $61+$ $34 \mathrm{ml} / \mathrm{m}^{2}$ and $93 \pm 37 \mathrm{ml} / \mathrm{m}^{2}$ respectively, but did not significantly reduced nor iESV neither iEDV in non responders that passed from $158+44 \mathrm{ml} / \mathrm{m}^{2}$ and $196 \pm 43 \mathrm{ml} / \mathrm{m}^{2}$ to $152 \pm 45 \mathrm{ml} / \mathrm{m}^{2}$ and to $184 \pm 44$ $\mathrm{ml} / \mathrm{m}^{2}$ respectively [3].

In responders the favourable effects of CRT are obtained within 2 months and are stable at least over a period of 6 months [8], but, possibly far longer. Consequently the determinants of CRT outcome are also the determinants of a further clinical course. In subjects with moderate left ventricular enlargement (iEDV $<142 \mathrm{ml} / \mathrm{m}^{2}$ ) and with LVEF not significantly lower than 0.24 CRT not only improves left ventricular performance $[2,3]$ but also preserves in time the obtained functional improvement [8]. In subjects with a severe left ventricular dysfunction (LVEF $\leq$ 0.20 and $\mathrm{iEDV}>142 \mathrm{ml} / \mathrm{m}^{2}$ ) no significant functional improvements are obtained by CRT with consequent poor prognosis [6].

In our series all the patients that developed hard events (death or acute heart failure requiring hospitalization) over a two year follow-up had a pre-CRT LVEF no higher than 0.21 with no significant changes after CRT. In a three year survival study [6] on a relatively small series of patients (mean age 74 years) we observed that the subjects died for a worsening heart failure, had pre-CRT iESV volumes > $194 \mathrm{ml} / \mathrm{m}^{2}$.

A very important left ventricular enlargement probably accounts for the nearly $30 \%$ of patients that do not take advantage from CRT [1, 7]. In the consideration that CRT is usually effective only in subjects with a moderate left ventricular enlargement and without an extremely depressed LVEF, we 
have suggested, since 2005, an early use of CRT in HF patients with LBBB $[2,5]$.

In conclusion: the effectiveness of CRT decreases with volume overload [8]. As we previously reported [8], this observation fully matches with the outcome of other cardiovascular interventions like coronary revascularization and valvular disease in which the benefit of the procedure is limited by the degree of volume overload [9, 10].

CRT must consequently be performed before the progressive increase in left ventricular dimensions compromise the effectiveness of the CRT itself, as also recently confirmed by Penn and associated [1].

\section{References}

1. Penn J, Goldenberg I, Moss AJ et al. Improved outcome with preventive cardiac resynchronization therapy in the elderly: A MADIT-CRT substudy. I Cardiovasc Electrophysiol 2011; 22: 892-897.

2. Valle G, Stanislao M, Gimelli A et al. Gated single photon emission computed tomography (g-SPECT) in predicting cardiac resynchronization therapy (CRT) effectiveness. Eur J Nucl Med Mol Imaging 2005; 32 (Suppl. 1): S165.

3. Gimelli A, Stanislao M, Valle G et al. Volume overload modulates beneficial effects of reperfusion in patients un- dergoing cardiac resynchronisation therapy: results of the resync study. J Cardiovasc Med 2007; 8: 575-581.

4. Valle G, Stanislao M, Gimelli A et al. Ejection fraction and volume overload predict the long-term outcome of patients with heart failure undergoing cardiac resynchronization therapy. J Nuclear Cardiology 2007; 14 (suppl to n. 2): S7.

5. Valle G, Stanislao M, Gimelli A et al. Prediction of response and prognosis after cardiac resynchronisation therapy. Heart 2008; 94: 1496.

6. Valle G, Stanislao M, Gimelli A et al. Prognostic value of gated Single Photon Emission Computed Tomography (gSPECT) myocardial scintigraphy in predicting threeyear survival in candidates to cardiac resynchronization therapy (CRT). Europace 200911 (Suppl. 1): i53.

7. Gradaus R, Stuckenborg V, Löher A et al. Diastolic filling pattern and left ventricular diameter predict response and prognosis after cardiac resynchronization therapy. Heart 2008; 94: 1026-1031.

8. Gimelli A, Frumento P, Valle G et al. CRT in patients with heart failure: time course of perfusion and wall motion changes. Cardiol Res Pract 2010, Epub 2010 june 24th.

9. Lee TH, Hamilton MA, Stevenson LW et al. Impact of left ventricular cavity size on survival in advanced heart failure. Am J Cardiol 1993; 72: 672-676.

10. Kim RW, Ugurlu BS, Tereb DA, Wackers FJ, Tellides G, Elefteriades JA. Effect of left ventricular volume on results of coronary artery bypass grafting. Am J Cardiol 2000; 11: 1261-1264. 